\title{
Bioequivalence of HX575 (Recombinant Human Epoetin Alfa) and a Comparator Epoetin Alfa after Multiple Subcutaneous Administrations
}

\author{
Fritz Sörgel $^{a} \quad$ Ursula Thyroff-Friesinger $^{b} \quad$ Andrea Vetter ${ }^{b}$ \\ Bernhard Vens-Cappellc Martina Kinzig ${ }^{a}$ \\ aIBMP Institute for Biomedical and Pharmaceutical Research, Nürnberg, ${ }^{b}$ Clinical Research, Hexal AG, Holzkirchen, \\ and 'Scope International, Hamburg, Germany
}

\section{Key Words}

Biosimilar erythropoesis-stimulating agents $\cdot$ Epoetin •

Erythropoesis-stimulating agents $\cdot$ HX575, bioequivalence $\cdot$ HX575, subcutaneous administration • Pharmacokinetics •

Pharmacodynamics $\cdot$ Recombinant human epoetin alfa
Conclusions: HX575 and the comparator epoetin alfa were bioequivalent with respect to their PK/PD, supporting the conclusion that both, when administered subcutaneously, will be equally efficacious and may be interchangeable as therapy.

Copyright $\odot 2008$ S. Karger AG, Basel

\begin{abstract}
Aim: To compare the steady-state pharmacokinetics and pharmacodynamics (PK/PD) of two erythropoesis-stimulating agents (ESA), HX575 (Binocrit ${ }^{\circledR}$, Sandoz GmbH, Holzkirchen, Germany), human recombinant epoetin alfa approved as the first biosimilar ESA, and a comparator epoetin alfa, following multiple subcutaneous administrations. Methods: An open, randomized, parallel group study was conducted in 80 healthy adult males. Subjects were randomized to multiple subcutaneous doses of $100 \mathrm{lU} / \mathrm{kg}$ body weight of HX575 or of the comparator epoetin alfa 3 times weekly for 4 weeks. Results: The hematological profiles of both treatments were similar, as determined from the population mean curves and area under the effect curve (AUEC) ratios. HX575 met the predefined biosimilarity criteria with respect to the ratio and 90\% confidence interval of the AUEC $_{\mathrm{Hb}}(98.9 \%$ [97.7-100.2\%]), the primary PD endpoint. The PK of the two treatments were also similar as shown by the $\mathrm{AUC}_{0-48}$ ratios and $90 \%$ confidence intervals, 94.3\% [84.7-105.0\%] and 96.9\% [88.2$106.5 \%]$, respectively. Study medication was well tolerated and neutralizing anti-epoetin antibodies were not detected.
\end{abstract}

\section{Introduction}

Epoetin is a glycoprotein which stimulates red blood cell (RBC) production [1]. Patients with chronic renal failure have impaired epoetin production, which is the primary cause of their anemia $[2,3]$. Human recombinant epoetin or erythropoesis-stimulating agents (ESA) have been shown to stimulate erythropoiesis in anemic patients with chronic renal failure, both in those who do and those who do not require regular dialysis [3-12]. ESA are indicated for treatment of chemotherapy-induced anemia in cancer patients and to reduce the need for allogenic blood transfusions in patients with moderate anemia scheduled to undergo elective surgery [13-15]. In addition, human recombinant epoetin is indicated for patients at high risk for perioperative transfusions with significant, anticipated blood loss.

The aim of this study was to estimate the relative bioavailability and pharmacodynamics of HX 575 versus the comparator epoetin alfa at steady state following subcu-

\section{KARGER}

Fax +41613061234 E-Mail karger@karger.ch www.karger.com
(C) 2008 S. Karger AG, Basel

0031-7012/09/0832-0122\$26.00/0

Accessible online at:

www.karger.com/pha
Prof. Fritz Sörgel

Department of Research

IBMP Institute for Biomedical and Pharmaceutical Research

Paul-Ehrlich-Strasse 19, DE-90562 Nürnberg-Heroldsberg (Germany)

Tel. +49 911518 280, Fax +49911518 2820, E-Mail ibmp@osn.de 
taneous administration. The pharmacokinetic profile of epoetin and the hematological effects on hemoglobin were evaluated as a surrogate for therapeutic efficacy. The primary objective was to assess biosimilarity for the area under the effect curve (AUEC) of hemoglobin. Furthermore, the safety profiles of the two treatments were compared.

\section{Methods}

This open, randomized, parallel group study enrolled 80 healthy male volunteers. Eligible subjects were $18-45$ years of age, physically and mentally healthy as confirmed by an interview, medical history, and clinical and laboratory examination. Other inclusion criteria were: a body mass index of $19-28 \mathrm{~kg} / \mathrm{m}^{2}$; hemoglobin $(\mathrm{Hb})$ concentrations of $13-15 \mathrm{~g} / \mathrm{dl}$; the percentage of reticulocytes (Ret\%, percentage of RBCs in the reticulocyte stage) $\leq 3 \%$ at screening, and normal or minor deviating iron parameters (iron deficiency was defined as ferritin $<10 \mathrm{ng} / \mathrm{ml}$ or Fe/TIBC ratio (transferrin saturation) $<12 \%)$. Subjects had to be nonsmokers or moderate smokers ( $\leq 10$ cigarettes/day) and abstain from alcohol for $48 \mathrm{~h}$ prior to each dose administration. Only male subjects were enrolled in order to minimize inter-subject variability, since female subjects are expected to show a higher variability due to the menstrual cycle.

Subjects were not eligible if their medical history showed evidence of any of the following: clinically significant abnormalities that might influence the absorption, distribution, metabolism or excretion of the active agent under investigation; cardiovascular disorders; presence of anti-epoetin antibody; increased values (above upper limit of normal range) of reticulocytes, erythrocytes, platelets, or serum potassium; use of systemic androgens within 2 months prior to study start; use of any medication (including over-the-counter medication) that was not explicitly permitted within 2 weeks prior to study start; epoetin therapy within 8 weeks before study start.

An iron supplement (100 mg twice daily) was administered to all subjects during the study. Except for paracetamol, all other concomitant use of drugs was restricted.

The study was conducted in Germany in accordance with the Declaration of Helsinki, Good Clinical Practice, and Good Laboratory Practice. The study was approved by an independent ethics committee and all volunteers gave their written informed consent.

Eligible subjects were randomized to receive a subcutaneous injection of one of two different treatments 3 times weekly for 4 weeks. HX575 treatment consisted of an injection of $100 \mathrm{IU} / \mathrm{kg}$ body weight of human recombinant epoetin alfa (Binocrit ${ }^{\circledR}$; Sandoz GmbH, Holzkirchen, Germany). The comparator treatment consisted of an injection of $100 \mathrm{IU} / \mathrm{kg}$ body weight of epoetin alfa (Erypo $^{\circledR} /$ Eprex $^{\circledR}$; Ortho Biotech, Neuss, Germany). Both groups received an injection by means of a syringe with a cannula for subcutaneous (abdominal wall) administration on days 1, 3, 5, 8, $10,12,15,17,19,22,24$ and 26 . Both HX575 and the comparator epoetin alfa were supplied as $10,000 \mathrm{IU} / \mathrm{ml}$ formulations. Subjects fasted for at least $8 \mathrm{~h}$ prior to and $2 \mathrm{~h}$ after administration. Beverages free of energy were allowed during this time.
Blood Sampling

For Ret\%, RBC count, $\mathrm{Hb}$ concentrations and HCT, blood samples of $3 \mathrm{ml}$ were drawn: on day 1 , three samples within $1 \mathrm{~h}$ predose with an interval of at least $10 \mathrm{~min}$, and just before dosing, on days $3,5,8,10,12,15,17,19,22,24$, and 26 just before dosing, and on day 29 at $72 \mathrm{~h}$ after the last dose.

For determination of transferrin, transferrin receptor, ferritin, and serum iron concentrations, venous blood samples of $12 \mathrm{ml}$ were drawn on days $1,12,19$ and 26 at the time of dosing.

For anti-epoetin antibody assays in serum, a blood sample of $6 \mathrm{ml}$ was drawn on days 15 and 29 at the time of dosing.

For serum epoetin assays, blood samples of $4 \mathrm{ml}$ were drawn: three samples within $1 \mathrm{~h}$ predose with an interval of at least 10 min, just before dosing, and at $0.5,1,2,3,4,5,6,8,10,12,14,16$, 24,36 , and $48 \mathrm{~h}$ after the first dosing on day 1 ; on days $8,15,19$, and 22 at the time of dosing, and at $0,0.5,1,2,3,4,5,6,8,10,12$, and $14,16,24,36$, and $48 \mathrm{~h}$ after dosing on day 24 .

All sample analyses were performed in the same laboratories. Reticulocyte (Ret) count, RBC count, Hb concentrations and hematocrit (HCT) were analyzed at LPT Laboratory for Pharmacology and Toxicology KG, Hamburg, Germany. Transferrin, ferritin and serum iron were determined at MDS Pharma Services Central Lab GmbH, Hamburg, Germany. Transferrin receptor was determined at Dres. Fenner and Partner, Hamburg, Germany. Serum anti-epoetin antibodies were determined at Hexal Biotech Forschungs GmbH, Oberhaching, Germany. Serum epoetin concentration measurements were performed at GTF, Gesellschaft für Therapeutische Forschung mbH, Nürnberg-Heroldsberg, Germany.

\section{Pharmacokinetic Assay and Evaluation}

For ELISA (enzyme-linked immunosorbent assay) determination of the concentrations of epoetin in human serum, a precise enzyme immunoassay kit (Quantikine ${ }^{\circledR}$ IVD $^{\circledR}$; R\&D Systems GmbH, Wiesbaden-Nordenstadt, Germany) was used. The procedure was validated according to international guidelines. During sample analysis, the standard curve was linear between 2.5 and $200.0 \mathrm{mIU} / \mathrm{ml}$ for all sequences and the lower limit of quantification for epoetin was $2.5 \mathrm{mIU} / \mathrm{ml}$. Samples expected to exceed the upper limit of the linear range were diluted before analysis with Specimen diluent of the enzyme immunoassay kit. The inter-day precision of the control standard of epoetin in human serum ranged from 5.0 to $7.5 \%$.

Pharmacokinetic variables were calculated by non-compartmental analysis using actual data and concentrations corrected for baseline values ( $\delta$ ) of endogenous epoetin. The primary pharmacokinetic parameter was the epoetin area under curve, $\mathrm{AUC}_{0-48, \mathrm{md}}$. Secondary parameters were $\mathrm{AUC}_{0-48, \mathrm{sd}}, \delta \mathrm{AUC}_{0-48, \mathrm{sd}}$, $\delta \mathrm{AUC}_{0-48, \operatorname{md}}, \mathrm{C}_{\max , \mathrm{sd}}, \delta \mathrm{C}_{\max , \mathrm{sd}}, \mathrm{C}_{\max , \mathrm{md}}, \delta \mathrm{C}_{\max , \operatorname{md}}, \mathrm{t}_{\max , \mathrm{sd}}$, $t_{\max m d}, t_{1 / 2, s d}, t_{1 / 2, m d}, P T F$, and $C_{\min }$. The treatments were considered to be bioequivalent when the ratio (HX575/comparator) and the $90 \%$ confidence interval (CI) for the $\mathrm{AUC}_{0-48, \mathrm{sd}}, \mathrm{C}_{\max , \mathrm{sd}}, \mathrm{t}_{1 / 2, \mathrm{sd}}$, $\mathrm{AUC}_{0-48, \mathrm{md}}, \mathrm{C}_{\text {max, md }}$, and $\mathrm{t}_{1 / 2}$, md fell within the acceptance range of $80-125 \%$.

\section{Pharmacodynamic Analyses}

The time courses of $\mathrm{Hb}, \mathrm{RBC}, \mathrm{HCT}$, and Ret\% were used as surrogate parameters for efficacy. The pharmacodynamic action of epoetin was determined as the total AUEC during 12 dosage intervals in 4 weeks for $\mathrm{Hb}, \mathrm{RBC}, \mathrm{HCT}$, and Ret\%, which were cal- 
culated by linear trapezoidal integration. The $\mathrm{AUEC}_{\mathrm{Hb}}$ was considered the primary variable. The formulations were considered to be biosimilar if the $90 \% \mathrm{CI}$ of the $\mathrm{AUEC}_{\mathrm{Hb}}$ ratio fell within a range of $96.8-103.2 \%$. The rationale for this acceptance range was the following: based on results from a pilot study, the $\mathrm{Hb}$ concentration was estimated to change by about $3 \mathrm{~g} / \mathrm{dl}$ within 4 weeks of the multiple dose regimen of the present study. A difference between the treatments of $\pm 1 \mathrm{~g} / \mathrm{dl}$ is considered acceptable, since under clinical conditions tight monitoring of the $\mathrm{Hb}$ concentrations is mandatory, and no dose adjustment for epoetin is required if the $\mathrm{Hb}$ concentrations are stable within a range of $\pm 1 \mathrm{~g} / \mathrm{dl}$. Furthermore, in clinical studies, a threshold of $-1.0 \mathrm{~g} / \mathrm{dl} \mathrm{Hb}$ has been used as the greatest clinically acceptable difference to demonstrate noninferiority [16]. The baseline Hb concentration in healthy volunteers was expected to be approximately $14 \mathrm{~g} / \mathrm{dl}$. The expected concentrations at the end of 4 weeks' treatment thus were approximately $17 \pm 1 \mathrm{~g} / \mathrm{dl}$. This translates into an AUEC $_{\mathrm{Hb}}$ of $(14+17 \pm$ 1) $/ 2=15.5 \pm 0.5 \mathrm{month} \cdot \mathrm{g} / \mathrm{dl}$. The absolute deviation of \pm 0.5 from the mean 15.5 translated into a relative acceptable difference for the ratio of $(0.5 / 15.5) \cdot 100 \%=3.2 \%$, which led to the corresponding acceptance boundaries for the ratio of $96.8-103.2 \%$. For the AUEC ratios (HX575/comparator) and 90\% CI of RBC, HCT, and Ret\%, no acceptance ranges were derived. Nevertheless, the AUEC ratios and $90 \%$ CI were compared in an exploratory fashion with the standard bioequivalence range of $80-125 \%$. Additionally, the time courses of transferrin receptor, transferrin, ferritin, and iron concentrations were investigated.

\section{Safety}

Adverse events were obtained from spontaneous reporting by the subjects or from responses to non-leading questions from the clinical staff. Outcome, therapy and contingent changes in study dosing were documented.

\section{Statistical Methods}

Sample size was determined as follows. An inter-individual coefficient of variation of approximately $3.8 \%$ was expected for the (log-transformed) AUEC $_{\mathrm{Hb}}$ [1]. A minimum of 37 subjects per treatment group had to complete the study to determine the relative pharmacodynamic efficiency in terms of the AUEC ratio (HX575/comparator) with an adequate precision in an analogous way to a bioequivalence study; the $90 \% \mathrm{CI}$ of the $\mathrm{AUEC}_{\mathrm{Hb}}$ ratio should fall within a range of $96.8-103.2 \%$ with a power of $>80 \%$, provided the true ratio is within 99 and $101 \%$. For the pharmacokinetic variable $\mathrm{AUC}_{0-48, \mathrm{md}}$, a coefficient of variation of $28 \%$ was expected from a previous study. 33 subjects were required per group to determine the precision of the relative bioavailability in such a way that the $90 \%$ CI of the ratio fell within an acceptance range of $80-125 \%$ with a power of $>80 \%$, provided the true ratio was within a range of $95-105 \%$. The analysis population for each of the treatments comprised 37 subjects.

The mean, standard deviation, coefficient of variation, range and median were calculated for each parameter. For concentration-related parameters as well, the geometric mean (GeoM) and the coefficient of variation of the geometric mean (GeoCV) were determined. For AUEC, $\mathrm{AUC}_{0-48, \mathrm{sd}}, \mathrm{AUC}_{0-48, \mathrm{md}}, \mathrm{C}_{\max , \mathrm{sd}}$, $\mathrm{C}_{\max , \mathrm{md}}, \mathrm{t}_{1 / 2, \mathrm{sd}}$, and $\mathrm{t}_{1 / 2, \mathrm{md}}$, the parametric point estimators for the ratio and the shortest $90 \%$ CIs were calculated using the LSMEANS and the root of residual mean squares from the ANOVA of log-transformed data with subsequent exponential trans-
Table 1. Demographic characteristics

\begin{tabular}{lcc}
\hline $\begin{array}{l}\text { Demographic } \\
\text { characteristic }\end{array}$ & $\begin{array}{c}\text { HX575 } \\
(\mathrm{n}=40)\end{array}$ & $\begin{array}{l}\text { Comparator } \\
(\mathrm{n}=40)\end{array}$ \\
\hline $\begin{array}{l}\text { Age, years } \\
\text { Mean }\end{array}$ & & \\
SD & 36.5 & 33.9 \\
$\quad$ Range & 6.4 & 7.0 \\
\hline Weight, kg & $21-45$ & $18-45$ \\
Mean & & \\
SD & 78.5 & 77.0 \\
Range & 8.4 & 9.7 \\
\hline Height, cm & $61-97$ & $56-97$ \\
Mean & & \\
SD & 179.9 & 180.0 \\
Range & 5.9 & 6.4 \\
\hline BMI & $168-203$ & $166-193$ \\
Mean & & \\
SD & 24.25 & 23.77 \\
Range & 2.23 & 2.57 \\
\hline
\end{tabular}

$\mathrm{n}=$ Number of subjects receiving treatment; $\mathrm{SD}=$ standard deviation; $\mathrm{BMI}=$ body mass index, measured as weight in $\mathrm{kg} / \mathrm{m}^{2}$ height.

formation [17]. The CIs for $\mathrm{AUEC}_{\mathrm{Hb}}, \mathrm{AUEC}_{\mathrm{HCT}}, \mathrm{AUEC}_{\mathrm{RBC}}$, and AUEC $_{\text {RET\% }}$ were calculated using a covariance analysis after adjusting the respective LSMEANS under both treatments for the respective predose values. Non-parametric point estimators for the ratios of expected medians of the treatments and the corresponding non-parametric $90 \%$ CIs were calculated based on the Mann-Whitney-Wilcoxon statistics using log-transformed data $[18,19]$. For $t_{\max }$, the non-parametric point estimator and the nonparametric $90 \%$ CIs for the difference of expected medians were calculated according to the Mann-Whitney-Wilcoxon statistics using the untransformed data.

\section{Results}

Eighty healthy adult males were enrolled, 40 subjects per treatment. 74 subjects completed the study and were available for pharmacodynamic and pharmacokinetic evaluations. Six volunteers withdrew from the study, 3 receiving HX575 and 3 receiving the comparator treatment. Reasons for withdrawal were: missing of too many administrations due to $\mathrm{Hb}$ elevation $>18 \mathrm{mg} / \mathrm{dl}$ (1 subject receiving HX575 dropped out on day 24 and 1 receiving the comparator treatment on day 23); positive drug test at second admission (1 subject each from both treatments were withdrawn on day 23); inability to come for treat- 
Table 2. Mean pharmacokinetic parameters after a single subcutaneous epoetin dose

\begin{tabular}{|c|c|c|c|c|c|c|}
\hline Treatment & $\begin{array}{l}\mathrm{AUC}_{0-48, \mathrm{sd}} \\
\mathrm{mIU} / \mathrm{ml} \cdot \mathrm{h}\end{array}$ & $\begin{array}{l}\delta \mathrm{AUC}_{0-48, \mathrm{sd}} \\
\mathrm{mIU} / \mathrm{ml} \cdot \mathrm{h}\end{array}$ & $\begin{array}{l}\mathrm{C}_{\max , \mathrm{sd}} \\
\mathrm{mIU} / \mathrm{ml}\end{array}$ & $\begin{array}{l}\delta \mathrm{C}_{\max , \mathrm{sd}} \\
\mathrm{mIU} / \mathrm{ml}\end{array}$ & $\begin{array}{l}t_{\max , s d} \\
h\end{array}$ & $\mathrm{t}^{\mathrm{h}_{1 / 2, \mathrm{sd}}}$ \\
\hline \multicolumn{7}{|l|}{ HX575 } \\
\hline Mean & $2,793.4$ & $2,356.6$ & 98.694 & 89.572 & 11.68 & 17.93 \\
\hline SD & 654.2 & 632.8 & 30.249 & 30.199 & 3.54 & 6.31 \\
\hline Min & $1,752.7$ & $1,464.5$ & 53.401 & 45.778 & 6.00 & 8.30 \\
\hline Median & $2,640.4$ & $2,184.4$ & 94.834 & 84.380 & 10.05 & 16.48 \\
\hline Max & $4,097.2$ & $3,684.2$ & 170.570 & 165.567 & 24.00 & 37.41 \\
\hline GeoM & $2,718.9$ & $2,277.1$ & 94.299 & 84.827 & - & 16.97 \\
\hline GeoCV, \% & 24.1 & 26.9 & 31.5 & 34.5 & - & 34.3 \\
\hline \multicolumn{7}{|l|}{ Comparator } \\
\hline Mean & $3,031.2$ & $2,624.6$ & 109.700 & 101.154 & 11.95 & 18.54 \\
\hline $\mathrm{SD}$ & $1,032.9$ & 983.5 & 58.198 & 57.426 & 4.98 & 6.12 \\
\hline Min & $1,686.3$ & $1,227.7$ & 47.019 & 37.353 & 6.00 & 7.81 \\
\hline Median & $2,964.8$ & $2,617.2$ & 94.857 & 85.522 & 10.00 & 17.49 \\
\hline Max & $6,563.7$ & $6,331.2$ & 352.790 & 347.929 & 24.00 & 32.94 \\
\hline GeoM & $2,883.5$ & $2,473.7$ & 99.422 & 90.608 & - & 17.60 \\
\hline GeoCV, \% & 32.2 & 35.3 & 44.6 & 47.5 & - & 34.0 \\
\hline
\end{tabular}

$\mathrm{AUC}_{0-48, \text { sd }}=$ Area under total concentration curve from 0 to $48 \mathrm{~h}$ after single dose; $\delta \mathrm{AUC}_{0-48, \text { sd }}=$ baseline-adjusted area under total concentration curve from 0 to $48 \mathrm{~h}$ after single dose; $C_{\max , s d}=$ peak serum concentration after single dose; $\delta C_{\max , \text { sd }}=$ baselineadjusted peak serum concentration after single dose; $t_{\max , s d}=$ time to $C_{\max }, \mathrm{sd} ; \mathrm{t}_{1 / 2, \mathrm{sd}}=$ terminal elimination half-life; $\mathrm{SD}$ = standard deviation; GeoM = geometric mean; $\mathrm{GeoCV}=$ coefficient of variation of GeoM.

* Calculated from 36 subjects (HX575) and 34 subjects (comparator). For all other parameters: $\mathrm{n}=37$. ment (1 subject receiving HX575 treatment, on day 25), and withdrawal of consent (1 subject receiving the comparator treatment, on day 19). These subjects were not replaced. Demographic data of enrolled subjects are presented in table 1.

\section{Pharmacokinetics}

The mean $( \pm \mathrm{SD})$ predose endogenous epoetin concentration was $9.1 \pm 4.2 \mathrm{mIU} / \mathrm{ml}$ in the HX575 group and $8.5 \pm 3.7 \mathrm{mIU} / \mathrm{ml}$ in the comparator group. The first injection resulted in a continuous increase reaching a maximum at $10.05 \mathrm{~h}$ (HX575) and $10.00 \mathrm{~h}$ (comparator) after dosing (medians, table 2). The mean serum epoetin concentration had increased by $89.6 \pm 30.2$ $\mathrm{mIU} / \mathrm{ml}$ (HX575) and by $101.2 \pm 57.4 \mathrm{mIU} / \mathrm{ml}$ (comparator). The mean trough concentrations $(28.8 \pm 9.3$ $\mathrm{mIU} / \mathrm{ml}$ (HX575) and $30.5 \pm 7.4 \mathrm{mIU} / \mathrm{ml}$ (comparator)) were about 3 times the endogenous baseline concentration at $48 \mathrm{~h}$ after the first application. The $\mathrm{AUC}_{0-48 \text {, sd }}$ was $2,718.9 \mathrm{mIU} / \mathrm{ml} \cdot \mathrm{h}(24.1 \%)$ after HX575 and 2,883.5 $\mathrm{mIU} / \mathrm{ml} \cdot \mathrm{h}$ (32.2\%) after the comparator (GeoM $(\mathrm{GeoCV})$ ).

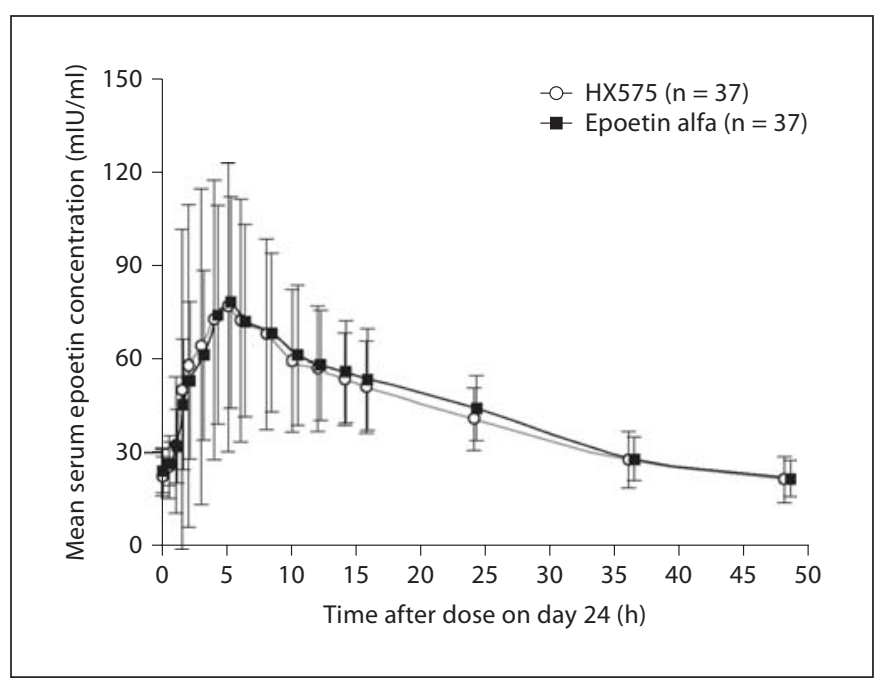

Fig. 1. Mean serum epoetin concentration-versus-time profiles $( \pm$ SD) after multiple doses not corrected for baseline epoetin levels. $0 \mathrm{~h}=$ Time of 11 th application on study day 24 . 
Table 3. Mean pharmacokinetic parameters after multiple subcutaneous epoetin doses

\begin{tabular}{|c|c|c|c|c|c|c|}
\hline Treatment & $\begin{array}{l}\mathrm{AUC}_{0-48, \mathrm{md}} \\
\mathrm{mIU} / \mathrm{ml} \cdot \mathrm{h}\end{array}$ & $\begin{array}{l}\delta \mathrm{AUC}_{0-48, \mathrm{md}} \\
\mathrm{mIU} / \mathrm{ml} \cdot \mathrm{h}\end{array}$ & $\begin{array}{l}\mathrm{C}_{\max , \mathrm{md}} \\
\mathrm{mIU} / \mathrm{ml}\end{array}$ & $\begin{array}{l}\delta \mathrm{C}_{\max , \mathrm{md}} \\
\mathrm{mIU} / \mathrm{ml}\end{array}$ & $\begin{array}{l}\mathrm{t}_{\max , \mathrm{md}} \\
\mathrm{h}\end{array}$ & $\begin{array}{l}\mathrm{t}_{1 / 2, \mathrm{md}^{*}} \\
\mathrm{~h}\end{array}$ \\
\hline \multicolumn{7}{|l|}{ HX575 } \\
\hline Mean & $2,044.9$ & $1,613.0$ & 82.410 & 73.288 & 8.74 & 18.28 \\
\hline $\mathrm{SD}$ & 587.9 & 601.8 & 48.690 & 48.753 & 6.15 & 8.50 \\
\hline Min & $1,148.9$ & 88.5 & 34.111 & 8.319 & 3.03 & 5.38 \\
\hline Median & $1,976.6$ & $1,507.3$ & 73.190 & 64.076 & 6.00 & 15.75 \\
\hline $\operatorname{Max}$ & $4,445.6$ & $3,906.2$ & 338.460 & 327.164 & 36.00 & 36.48 \\
\hline GeoM & $1,977.5$ & $1,465.9$ & 75.238 & 64.092 & - & 16.30 \\
\hline GeoCV, \% & 25.8 & 59.9 & 40.3 & 56.6 & - & 53.9 \\
\hline \multicolumn{7}{|l|}{ Comparator } \\
\hline Mean & $2,095.0$ & $1,686.2$ & 82.817 & 74.271 & 9.20 & 18.16 \\
\hline $\mathrm{SD}$ & 486.4 & 429.1 & 34.056 & 33.001 & 5.42 & 7.52 \\
\hline Min & $1,231.0$ & 981.2 & 44.216 & 37.637 & 5.00 & 6.42 \\
\hline Median & $2,016.3$ & $1,618.9$ & 71.236 & 62.049 & 6.00 & 19.86 \\
\hline Max & $3,171.5$ & $2,777.5$ & 172.980 & 155.542 & 24.00 & 42.58 \\
\hline GeoM & $2,040.6$ & $1,635.1$ & 77.104 & 68.308 & - & 16.65 \\
\hline GeoCV, \% & 23.7 & 25.5 & 38.6 & 42.0 & - & 45.5 \\
\hline
\end{tabular}

$\mathrm{AUC}_{0-48, \mathrm{md}}=$ Area under total concentration curve from 0 to $48 \mathrm{~h}$ after multiple doses; $\delta \mathrm{AUC} \mathrm{C}_{0-48, \mathrm{md}}=$ baseline-adjusted area under total concentration curve from 0 to $48 \mathrm{~h}$ after multiple doses; $\mathrm{C}_{\max , \mathrm{md}}=$ peak serum concentration after multiple doses; $\delta \mathrm{C}_{\max , \mathrm{md}}=$ baseline-adjusted peak serum concentration after multiple doses; $t_{\max , m d}=$ time to $\mathrm{C}_{\max , \mathrm{md}} ; \mathrm{t}_{1 / 2, \mathrm{md}}=$ terminal elimination half-life; $\mathrm{SD}=$ standard deviation; $\mathrm{GeoM}=$ geometric mean; GeoCV = coefficient of variation of GeoM.

* Calculated from 34 subjects (HX575) and 35 subjects (comparator). For all other parameters: $\mathrm{n}=37$.

The multiple dose concentration-versus-time profiles (fig. 1) were similar to the single dose profiles. On study day 24 , the mean trough concentrations $(22.2 \pm 6.3 \mathrm{mIU} /$ $\mathrm{ml}$ (HX575) and $24.0 \pm 7.0 \mathrm{mIU} / \mathrm{ml}$ (comparator)) were more than twice the endogenous baseline concentrations. The $\mathrm{C}_{\max , \text { md }}$ was reached $6.0 \mathrm{~h}$ (median) after the preceding dose for both treatments (table 3). Mean serum epoetin concentrations had increased with $73.3 \pm 48.8 \mathrm{mIU} /$ $\mathrm{ml}$ (HX575) and $74.3 \pm 33.0 \mathrm{mIU} / \mathrm{ml}$ (comparator). The AUC $_{0-48, \text { md }}$ was $1,977.5 \mathrm{mIU} / \mathrm{ml} \cdot \mathrm{h}(25.8 \%)$ after HX575 and $2,040.6 \mathrm{mIU} / \mathrm{ml} \cdot \mathrm{h}(23.7 \%)$ after the comparator (GeoM (GeoCV)).

Comparison of the baseline-adjusted $\delta \mathrm{AUC}_{0-48, \mathrm{md}}$ and $\delta C_{\max , \text { md }}$ (table 3 ) with the corresponding single dose $\delta A U C_{0-48, s d}$ and $\delta C_{\max , \text { sd }}$ (table 2) demonstrated that there was no accumulation after either treatment. The multiple dose values were even lower than the corresponding single dose values. An increase in mean epoetin levels was observed in both treatment groups, as visible by an increased $\mathrm{C}_{\min }(19.2 \pm 6.0 \mathrm{mIU} / \mathrm{ml}$ (HX575), $20.8 \pm 5.4 \mathrm{mIU} / \mathrm{ml}$ (comparator)) compared to the pretreatment baseline levels.
The peak trough fluctuation (PTF) of epoetin was similar for both treatments (GeoM (GeoCV) 1.32 (38.0\%) after HX575 versus 1.27 (40.3\%) after the comparator). The terminal half-life was similar for the two treatments and was only slightly shorter after multiple doses (table 3) than after the single dose (table 2).

The ratios of the pharmacokinetic parameters of epoetin were calculated to compare the average bioavailability of the epoetin from the two investigated formulations (table 4). The pretreatment baseline epoetin concentrations were comparable for both treatment groups as indicated by the ratio and 90\% CI of 108.6\% [92.1-128.1\%]. After single and multiple epoetin doses, the ratios and $90 \%$ CIs of the $\mathrm{AUC}_{0-48}$ and the $\mathrm{C}_{\max }$ fell within the common acceptance range for bioequivalence of $80-125 \%$ (table 4). The expected median for the $t_{\max }$ difference was 0 . The formulations also showed similarity with respect to the ratio and $90 \%$ CI of the $t_{1 / 2}$ (table 4 ). HX575 was therefore pharmacokinetically equivalent to the comparator epoetin alfa following both single and multiple subcutaneous administrations. 


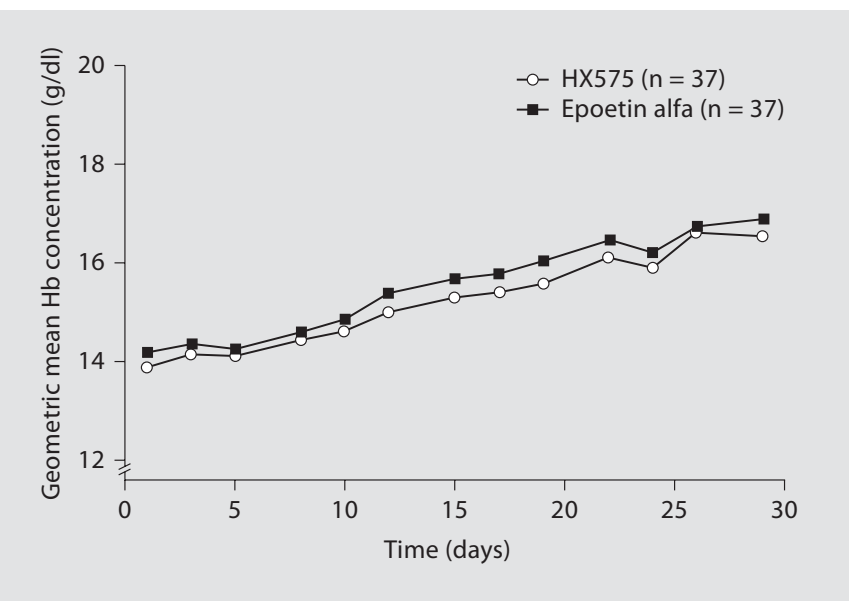

Fig. 2. Geometric mean hemoglobin concentration-versus-time profiles during treatment.

\section{Pharmacodynamics}

Comparing both treatment groups, the $\mathrm{Hb}$ baseline concentrations before treatment differed slightly (GeoM (GeoCV) $13.9 \mathrm{~g} / \mathrm{dl}$ (5.1\%) for the HX575 group and 14.2 $\mathrm{g} / \mathrm{dl}(5.0 \%)$ for the comparator group). The repeated epoetin administration resulted in an almost continuous increase during the treatment period. The mean curves for both treatments were almost congruent (fig. 2). At the end of the treatment period, the $\mathrm{Hb}$ had increased to $16.5 \mathrm{~g} / \mathrm{dl}$ (6.5\%) after HX575 and $16.9 \mathrm{~g} / \mathrm{dl}$ (6.3\%) after the comparator (GeoM (GeoCV)), corresponding to 117.9 and $119.4 \%$ of the respective pretreatment baselines. The $\mathrm{Hb}$ concentration $(\mathrm{GeoM} \pm \mathrm{CV})$ increased by $2.3 \pm 55.8 \mathrm{~g} / \mathrm{dl}$ (HX575) and $2.6 \pm 46.6 \mathrm{~g} / \mathrm{dl}$ (comparator) in 4 weeks.

The AUEC ${ }_{\mathrm{Hb}}$ was very similar for the two treatments (table 5). The ratio and 90\% CI for the $\mathrm{AUEC}_{\mathrm{Hb}}$ was calculated with the baseline as a covariable, because the predose baseline for $\mathrm{Hb}$ differed by $0.3 \mathrm{~g} / \mathrm{dl}$ between the two treatments. This reduced the inter-subject variability (ANOVA-CV) considerably from 4.9 to $3.2 \%$. The baseline-adjusted $\mathrm{AUEC}_{\mathrm{Hb}}$ ratio and $90 \% \mathrm{CI}$ fell within the stipulated acceptance range of $96.8-103.2 \%$ (table 5).

The mean curves for RBC counts (fig. 3) were similar for both treatments but parallel shifted, because the treatment groups started at slightly different baseline counts (GeoM (GeoCV) 4.6/pl (6.2\%) after HX575 and 4.8/pl (5.9\%) after the comparator). During epoetin treatment, the RBC counts increased almost continuously to $5.4 / \mathrm{pl}$ (6.1\%) after HX575 and 5.6/pl (6.4\%) after the comparator (GeoM (GeoCV)) on study day 29, corresponding to a relative count of 116 and $118 \%$, respectively. The treat-

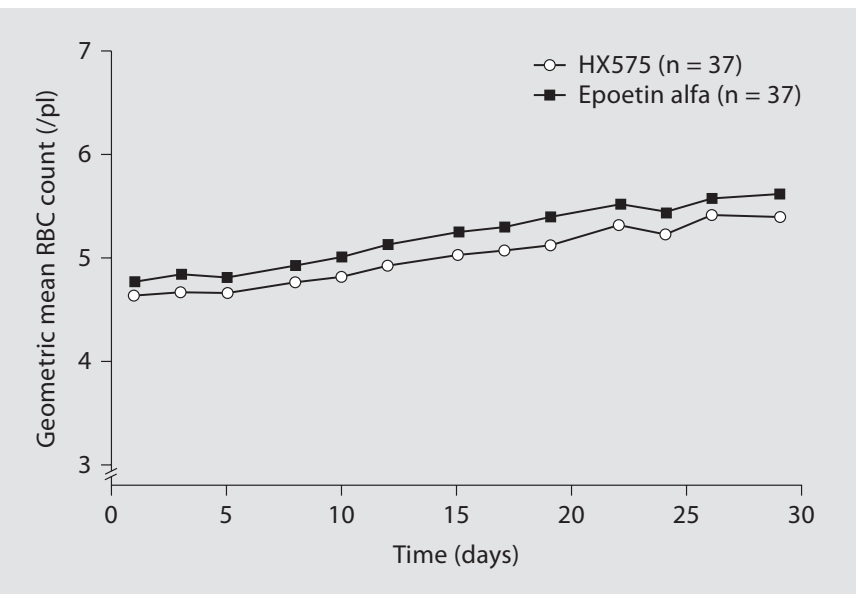

Fig. 3. Geometric mean RBC count-versus-time profiles during treatment.

Table 4. Ratio (HX575/comparator), 90\% confidence intervals (CI) and ANOVA coefficient of variation (ANOVA-CV) of pharmacokinetic $(\mathrm{PK})$ parameters after single and multiple epoetin doses

\begin{tabular}{lllll}
\hline $\begin{array}{l}\text { PK } \\
\text { parameter }\end{array}$ & Method & $\begin{array}{l}\text { Ratio } \\
\%\end{array}$ & $\begin{array}{l}90 \% \mathrm{CI} \\
\%\end{array}$ & $\begin{array}{l}\text { ANOVA- } \\
\mathrm{CV}, \%\end{array}$ \\
\hline AUC $_{0-48, \mathrm{sd}}$ & ANOVA-log & 94.3 & $84.7-105.0$ & 28.4 \\
$\mathrm{C}_{\max , \mathrm{sd}}$ & ANOVA-log & 94.8 & $82.1-109.5$ & 38.5 \\
$\mathrm{t}_{1 / 2, \mathrm{sd}}$ & ANOVA-log & 96.4 & $84.4-110.1$ & 34.2 \\
\hline $\mathrm{AUC}_{0-48, \mathrm{md}}$ & ANOVA-log & 96.9 & $88.2-106.5$ & 24.8 \\
$\mathrm{C}_{\max , \mathrm{md}}$ & ANOVA-log* & 97.6 & $84.2-113.1$ & 39.4 \\
$\mathrm{t}_{1 / 2, \mathrm{md}}$ & ANOVA-log & 97.9 & $81.0-118.2$ & 49.7 \\
\hline
\end{tabular}

$\mathrm{AUC}_{0-48}=$ Area under total concentration curve from 0 to $48 \mathrm{~h} ; \mathrm{C}_{\max }=$ peak serum concentration; $\mathrm{t}_{1 / 2}=$ terminal half-life; $\mathrm{sd}=$ single dose md = multiple dose; Method = method used to calculate $90 \%$ CI (ANOVA of log-transformed data).

* Deviation of ANOVA residuals from normal distribution $\mathrm{p}<0.05$. The treatments were considered bioequivalent if the ratio and $90 \% \mathrm{CI}$ fell within the range of $80-125 \%$.

ments were similar with respect to $\mathrm{RBC}$ production as shown by the $A U E C_{R B C}$ (table 5). The $A U E C_{R B C}$ ratio and $90 \%$ CI fell within the standard range for bioequivalence of $80-125 \%$ (table 5).

The shape of the mean curves for HCT was similar to that of $\mathrm{Hb}$ and $\mathrm{RBC}$ (fig. 4). The treatment groups started at mean baseline values of $0.411 / 1(5.0 \%)$ after HX575 and 0.41 1/1 (4.8\%) after the comparator (GeoM (GeoCV)). After 4 weeks of epoetin administration, the HCT had in- 


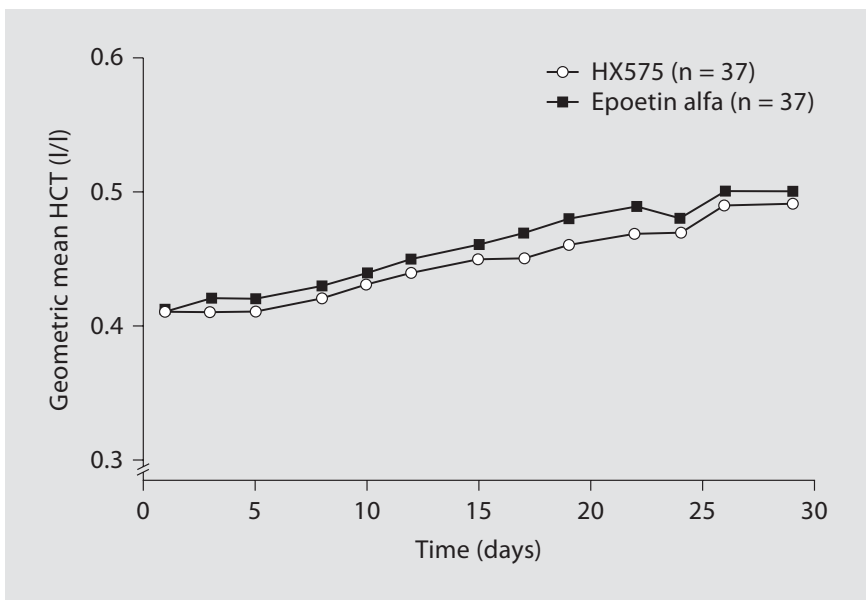

Fig. 4. Geometric mean HCT-versus-time profiles during treatment.

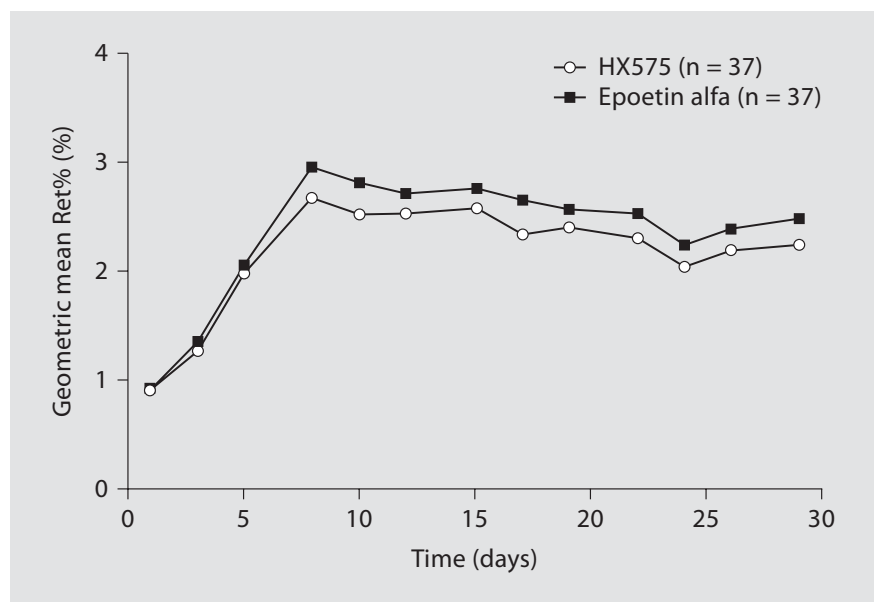

Fig. 5. Geometric mean reticulocyte percentage-versus-time profiles during treatment.

Table 5. Area under the effect curve (AUEC), AUEC ratio (HX575/comparator), 90\% CIs, and ANOVA coefficient of variation over days 1-29 of the study for the AUECs of the hematological parameters

\begin{tabular}{|c|c|c|c|c|c|c|}
\hline $\begin{array}{l}\text { Hematological } \\
\text { parameter }\end{array}$ & & HX575 & Comparator & $\begin{array}{l}\text { Ratio } \\
\%\end{array}$ & $\begin{array}{l}90 \% \text { CI } \\
\%\end{array}$ & $\begin{array}{l}\text { ANOVA-CV } \\
\%\end{array}$ \\
\hline $\begin{array}{l}\mathrm{AUEC}_{\mathrm{Hb}} \\
\mathrm{g} / \mathrm{dl} \cdot \mathrm{h}\end{array}$ & $\begin{array}{l}\text { GeoM } \\
\text { GeoCV }\end{array}$ & $\begin{array}{l}10,236.6 \\
4.9 \%\end{array}$ & $\begin{array}{l}10,457.7 \\
4.8 \%\end{array}$ & 98.9 & $97.7-100.2$ & 3.2 \\
\hline $\begin{array}{l}\mathrm{AUEC}_{\mathrm{RBC}} \\
1 / \mathrm{pl} \cdot \mathrm{h}\end{array}$ & $\begin{array}{l}\text { GeoM } \\
\text { GeoCV }\end{array}$ & $\begin{array}{l}3,373.28 \\
5.5 \%\end{array}$ & $\begin{array}{l}3,504.80 \\
5.8 \%\end{array}$ & 98.7 & $97.5-99.8$ & 2.9 \\
\hline $\begin{array}{l}\text { AUEC }_{\text {HCT }} \\
1 / l \cdot h\end{array}$ & $\begin{array}{l}\text { GeoM } \\
\text { GeoCV }\end{array}$ & $\begin{array}{l}300.0 \\
4.8 \%\end{array}$ & $\begin{array}{l}307.6 \\
4.4 \%\end{array}$ & 98.7 & $97.3-100.0$ & 3.4 \\
\hline $\begin{array}{l}\text { AUEC }{ }_{\text {RET }} \\
\% \cdot \mathrm{h}\end{array}$ & $\begin{array}{l}\text { GeoM } \\
\text { GeoCV }\end{array}$ & $\begin{array}{l}1,501.05 \\
18.7 \%\end{array}$ & $\begin{array}{l}1,634.33 \\
18.8 \%\end{array}$ & 93.4 & $88.3-98.8$ & 14.5 \\
\hline
\end{tabular}

GeoM = Geometric mean; GeoCV = coefficient of variation of GeoM; CI = confidence interval; ANOVA$\mathrm{CV}=$ ANOVA coefficient of variation. Method used to calculate the $90 \% \mathrm{CI}$ : ANCOVA on log-transformed data. The treatments were considered biosimilar if the ratio and $90 \% \mathrm{CI}$ of the AUEC $\mathrm{hb}$ fell within the range of 96.8-103.2\%. The other parameters were considered biosimilar if the respective AUEC ratio and $90 \%$ CI fell within the range of $80-125 \%$. Number of subjects analyzed: $n=37$.

creased to $0.49 \mathrm{l} / \mathrm{l}(6.1 \%)$ after HX575 and $0.50 \mathrm{l} / 1$ (6.0\%) after the comparator (GeoM (GeoCV)); 120 and $122 \%$ of the baseline, respectively. The $\mathrm{AUEC}_{\mathrm{HCT}}$ differed by only $2 \%$ between the treatments (table 5). The $\mathrm{AUEC}_{\mathrm{HCT}}$ ratio and $90 \% \mathrm{CI}$ fell within the standard bioequivalence range of $80-125 \%$ (table 5 ).

The Ret\%-versus-time profile revealed minor differences between the treatments (fig. 5). The predose baseline values were $0.90 \%$ (36.5\%) after HX575 and $0.95 \%$
(33.5\%) after the comparator (GeoM (GeoCV)). The increase started after the first application and continued until day 8 to a maximum of $2.66 \%$ (22.1\%) after HX575 and $2.96 \%(19.3 \%)$ after the comparator (GeoM (GeoCV)). Thereafter, the counts decreased consistently to values of 2.21\% (20.7\%) after HX575 and 2.48\% (19.2\%) after the comparator on study day 29 . At the end of the treatment interval (day 29), the Ret\% was still 245\% (HX575) and $261 \%$ (comparator) of the baseline value. 
The difference in cumulative response of the reticulocytes $\left(\right.$ AUEC RET\% $_{\text {) }}$ to the treatments was approximately 9\% (table 5). The percentage of reticulocytes was highly variable and the ANOVA-CV for the $\mathrm{AUEC}_{\mathrm{RET} \%}$ was considerably wider than that for $\mathrm{Hb}, \mathrm{HCT}$ and $\mathrm{RBC}$, because the Ret\% response to epoetin was biphasic; there was a positive response to the epoetin injections only during the first week, thereafter the relative reticulocyte content decreased while treatment continued. The ratio and $90 \%$ $\mathrm{CI}$ of the $\mathrm{AUEC}_{\text {Ret } \%}$ fell within the standard bioequivalence range of $80-125 \%$ (table 5).

The transferrin receptor concentrations increased continuously during repeated epoetin injections from a pretreatment baseline in the HX575 group of $2.6 \mathrm{mg} / \mathrm{l}$ $(34.7 \%)$ to $8.0 \mathrm{mg} / \mathrm{l}(18.2 \%)$ and in the comparator group from $2.7 \mathrm{mg} / \mathrm{l}(26.1 \%)$ to $8.9 \mathrm{mg} / \mathrm{l}$ (13.9\%) (GeoM $(\mathrm{GeoCV}))$. Ferritin concentrations decreased from baseline values of $42.1 \mu \mathrm{g} / \mathrm{l}(130.1 \%)$ to $22.4 \mu \mathrm{g} / \mathrm{l}(62.0 \%)$ after HX575 and from $48.7 \mu \mathrm{g} / \mathrm{l}$ (119.3\%) to $23.2 \mu \mathrm{g} / \mathrm{l}(46.4 \%)$ after the comparator (GeoM (GeoCV)), a decrease of about $50 \%$.

In contrast, the other pharmacodynamic variables showed only minor changes after repeated epoetin injections. The transferrin concentrations increased slightly from $2.5 \mathrm{~g} / \mathrm{l}(18.7 \%)$ to $2.8 \mathrm{~g} / \mathrm{l}(16.6 \%)$ after HX575 and from $2.5 \mathrm{~g} / \mathrm{l}(13.6 \%)$ to $2.8 \mathrm{~g} / \mathrm{l}$ (13.4\%) after the comparator (GeoM (GeoCV)). During HX575 treatment, the mean iron concentration decreased slightly from baseline values of $17.5 \mu \mathrm{mol} / \mathrm{l}(46.9 \%)$ to $15.0 \mu \mathrm{mol} / \mathrm{l}(96.5 \%)$, and during the comparator treatment from $17.9 \mu \mathrm{mol} / \mathrm{l}$ (40.5\%) to $10.9 \mu \mathrm{mol} / \mathrm{l}(60.1 \%)$ (GeoM (GeoCV)). The iron concentrations determined during treatment may have been influenced by the iron supplementation as well as by the pharmacodynamic action of epoetin. Considering the large variability, both effects either balanced each other out or there was no substantial effect on iron.

\section{Safety}

A total of 87 adverse events were reported during the study: 37 events during HX575 treatment and 50 events during the comparator treatment. The most frequently reported adverse events were headache, polycythemia, tiredness, common cold, diarrhea, nausea, stomach pain, chest pressure sensation, back pain, leg pain, and dizziness. The pattern of the adverse events considered to be related to the study medication revealed no relevant differences between each ESA. The number of adverse events seemed slightly higher for the comparator treatment, but this was regarded not to be clinically relevant.
Anti-epoetin antibodies were not found in subjects treated with HX575. Skin tolerability of the subcutaneous HX575 injections was similar to that of the comparator.

\section{Discussion}

The study was designed to estimate the relative bioavailability and pharmacodynamics with respect to the hematopoietic action of the new ESA, HX575, against a well-known comparator, epoetin alfa. The primary pharmacokinetic parameter was $\mathrm{AUC}_{0-48, \mathrm{md}}$. The primary objective of the study was to assess biosimilarity with respect to the hematopoietic action in terms of the AUEC $\mathrm{Hb}$. Furthermore, the safety profiles of the two treatments were compared.

The areas under the total epoetin curve $\left(\mathrm{AUC}_{0-48}\right)$ after single and multiple doses indicate a similar extent of epoetin exposure for both formulations. The $90 \%$ CI of the treatment ratios for $\mathrm{AUC}_{0-48, \mathrm{sd}}, \mathrm{C}_{\mathrm{max}, \mathrm{sd}}, \mathrm{AUC}_{0-48, \mathrm{md}}$, and $\mathrm{C}_{\max \text {, md }}$ indicated bioequivalence. Similarly, the efficacy of the treatments was biosimilar in terms of the AUEC $_{\mathrm{Hb}}$ ratio and $90 \% \mathrm{CI}$, which fell within the stipulated acceptance range of $96.8-103.2 \%$. No clinically significant differences between safety profiles of the two treatments were observed.

The primary endpoint for the evaluation of the efficacy was the effect of epoetin on $\mathrm{Hb}$ synthesis. The $\mathrm{Hb}$ concentrations increased after repeated epoetin doses within 4 weeks to 118\% (HX575) and 119\% (comparator) of the predose baseline. This increase was similar to that found for epoetin alfa in an earlier study with healthy volunteers [20].

The baseline-adjusted AUEC $_{\mathrm{Hb}}$ ratio and $90 \% \mathrm{CI}$ indicated biosimilarity for HX575 and the comparator epoetin alfa. The RBC and HCT concentrations were highly correlated with the $\mathrm{Hb}$ concentrations. The ratios and their $90 \%$ CIs of the baseline-adjusted AUEC $_{\mathrm{HCT}}$ and $A U E C_{R B C}$ were very similar to those of $A U E C_{H b}$.

The response of the reticulocytes to repeated epoetin injections differed from that of $\mathrm{Hb}, \mathrm{RBC}$, and HCT. The Ret\% increased rapidly within the first week to 3 times the pretreatment baseline and thereafter returned slowly. At the end of the treatment interval, the Ret\% was about 2.5 times as high as the baseline value. The variability of the reticulocytes of $18.7 \%$ (not baseline-adjusted) was considerably higher than that of the other hematopoietic parameters. The adjustment to the baseline slightly reduced the inter-subject variability to $14.5 \%$. 


\section{Conclusions}

The multiple doses of the study medication were well tolerated with no clinically relevant differences between safety profiles of the treatments compared. No neutralizing anti-epoetin antibodies could be detected under treatment. HX575 is pharmacokinetically comparable to the comparator epoetin alfa following both single and multiple subcutaneous administrations. Furthermore, HX575 met the predefined biosimilarity criteria with respect to the primary pharmacodynamic endpoint of this study, AUEC $_{\mathrm{Hb}}$. With respect to the predefined, secondary, hematopoietic endpoints of AUEC $_{\mathrm{HCT}}$ and $\mathrm{AUEC}_{\mathrm{RBC}}$, HX575, the first ESA to be approved as a biosimilar in Europe, and the comparator epoetin alfa were comparable. The results of this study support the conclusion that HX575 and the comparator epoetin alfa, when administered subcutaneously, will be equally efficacious and may be interchangeably used in therapy.

\section{Acknowledgments}

Reticulocyte count, RBC count, Hb concentrations and hematocrit were analyzed at LPT Laboratory for Pharmacology and Toxicology KG, Hamburg, Germany. Transferrin, ferritin and serum iron were determined at MDS Pharma Services Central Lab $\mathrm{GmbH}$, Hamburg, Germany. Transferrin receptor was determined at Dres. Fenner and Partner, Hamburg, Germany. Serum anti-epoetin antibodies were determined at Hexal Biotech Forschungs GmbH, Oberhaching, Germany. Serum epoetin concentration measurements were performed at GTF, Gesellschaft für Therapeutische Forschung mbH, Nürnberg-Heroldsberg, Germany. The authors would also like to thank Watermeadow Medical (Witney, UK) for assistance in the preparation of this article and would like to acknowledge the financial support of Sandoz Pharmaceuticals GmbH.

Declaration of competing interests: F. Sörgel has received a fee for speaking, funds for research and consulting fees; U. ThyroffFriesinger is an employee of Hexal AG and has a small amount of shares in the mother company; A. Vetter is an employee of Hexal AG; B. Vens-Cappell and Martina Kinzig have no competing interests to declare. Hexal AG is a subsidiary of Sandoz.

\section{References}

1 Graber SE, Krantz SB: Erythropoietin and the control of red cell production. Ann Rev Med 1978;29:51-66.

2 Eschbach JW, Adamson JW: Anemia of endstage renal disease. Kidney Int 1985;28:1-5.

3 Eschbach JW, Egrie JC, Downing MR, Browne JK, Adamson JW: Correction of the anemia of end-stage renal disease with recombinant human erythropoietin. N Engl J Med 1987;316:73-78.

4 Eschbach JW, Abdulhadi MH, Browne JK, Delano BG, Downing MR, Egrie JC, Evans RW, Friedman EA, Graber SE, Haley NR, et al: Recombinant human erythropoietin in anemic patients with end-stage renal disease. Results of a phase III multicenter clinical trial. Ann Intern Med 1989;111:9921000.

5 Eschbach JW, Egrie JC, Downing MR, Browne JK, Adamson JW: The use of recombinant human erythropoietin: effect in endstage renal disease; in Friedman EA, Beyer M, DeSanto NG, Giordano C (eds): Prevention of Chronic Uremia. Philadelphia, Field \& Wood Inc., 1989, pp 148-155.

6 Egrie JC, Eschbach JW, McGuire T, Adamson JW: Pharmacokinetics of recombinant human erythropoietin administered to hemodialysis patients (abstract). Kidney Int 1988;33:262.

7 Evans RW, Rader B, Manninen DL: The quality of life of hemodialysis recipients treated with recombinant human erythropoietin. JAMA 1990;263:825-830.
8 Paganini E, Garcia J, Ellis P, Bodnar D, Magnussen M: Clinical sequelae of correction of anemia with recombinant human erythropoietin; urea kinetics, dialyzer function and reuse (abstract). Am J Kidney Dis 1988;11: 16.

-9 Delano BG, Lundin AP, Galonsky R, Quinn RM, Rao TK, Friedman EA: Dialyzer urea and creatinine clearances not significantly changed in $\mathrm{r}$-HuEPO-treated maintenance hemodialysis patients (abstract). Kidney Int 1988;33:219.

10 Stivelman J, Van Wyck D, Ogden D: Use of recombinant erythropoietin with high flux dialysis does not worsen azotemia or shorten access survival (abstract). Kidney Int 1988; 33:239.

11 Lim VS, DeGowin RL, Zavala D, Kirchner PT, Abels R, Perry P, Fangman J: Recombinant human erythropoietin treatment in pre-dialysis patients: a double-blind placebo-controlled trial. Ann Intern Med 1989; 110:108-114.

12 Stone WJ, Graber SE, Krantz SB, Dessypris EN, O’Neil VL, Olsen NJ, Pincus TP: Treatment of the anemia of pre-dialysis patients with recombinant human erythropoietin: a randomized, placebo-controlled trial. Am J Med Sci 1988;296:171-179.

13 De Andrade JR, Jove M: Baseline hemoglobin as a predictor of risk of transfusion and response to epoetin alfa in orthopedic surgery patients. Am J Orthoped 1996;25:533542.
14 Goldberg MA, McCutchen JW: A safety and efficacy comparison of two dosing regimens of epoetin alfa in patients undergoing major orthopedic surgery. Am J Orthoped 1996;25: 544-552.

15 Faris PM, Ritter MA: The effects of recombinant human erythropoietin on perioperative transfusion requirements in patients having a major orthopaedic operation. J Bone Joint Surg Am 1996;78:62-72.

-16 Nissenson AR, Swan SK, Lindberg JS, Soroka SD, Beatey R, Wang C, Picarello N, McDermott-Vitak A, Maroni BJ: Randomized, controlled trial of darbepoetin alfa for the treatment of anemia in hemodialysis patients. Am J Kidney Dis 2002;40:110-118.

17 Chow SC, Liu JP: Design and Analysis of Bioavailability and bioequivalence Studies. Hong Kong, Dekker, 1992.

18 Hollander M, Wolfe DA: Nonparametric Statistical Methods. The Two Sample Problem. New York, Wiley, 1973.

19 Hauschke D, Steinijans VW, Diletti E: A distribution-free procedure for the statistical analysis of bioequivalence studies. Int J Clin Pharmacol Ther Toxicol 1992;30(suppl 1): 37-43.

20 Cheung W, Minton N, Gunawardena K: Pharmacokinetics and pharmacodynamics of epoetin alfa once weekly and three times weekly. Eur J Clin Pharmacol 2001;57:411418. 